\title{
A CONSTRUÇÃO DA IDENTIDADE DO FEMININO : PRAGMATISMO, IMAGINÁRIO E SIMBÓLICO
}

\section{Dina Maria Martins Ferreira ${ }^{(*)}$}

Resumo: Este artigo visa trabalhar o constructo identitário do feminismo em desempenho político, tendo como base discursos mediáticos. A questão do processo desgnativo vai se desenvolver primeiro por uma semântica filosófica, na qual a relação entre referência e designação é estabelecida por valores ideológicos do momento histórico em que se instauram. Junto à questão do utilitarismo político no ato designativo, percebe-se a presença de um imaginário cultural e duas aparentes polaridades - instante e permnencia -que se entrecruzavam em um concívio paradoxal.

Palavras-chave: Mídia; designação; utilitarismo; imaginário; político

Este trabalho visa argumentar como a designação faz-se preponderante na manifestação e construção da identidade do feminino. Vai-se discutir essa temática, primeiramente sob o ângulo de uma semântica filosófica, no qual a relação entre referência e designação é provida de valores ideológicos do momento histórico em que se insere, inventariando, assim, objetivos e interesses daqueles que os empregam. E segundo, indaga-se se pelo/no ato de fala a designação não reflete, de alguma forma, o produto de uma sistema simbólico, se designação não é mediação de uma forma cultural especificada na própria prática, e se o uso de língua não está sujeito a formulações designativas específicas da cultura. Assim sendo, a multivocidade de usos designativos em língua apresenta tendência à univocidade cultural de símbolos.

O vocabulário será retirado do discurso midiático, Por uma república melhor, de Carlos Heitor Cony, jornal Folha de S. Paulo, de 6 de junho de 2002, e A dona do Alvorada, de Tina Vieira, Companheira Marisa de Antônia Márcia Vale, revista Isto É, de 8 de janeiro de 2003, e revista Época, de 3 de fevereiro de 2003. Fixa-se o

(") Professora da Universidade Presbiteriana Mackenzie. Doutora em Linguística pela UFRJ. Pós-doutora em Pragmática pela Unicamp 
corpus no discurso midiático, por se tratar de uma linguagem que reflete representações sócio-ideológicas de uma cultura. A escolha dos três textos deve-se em primeiro lugar ao fato de figurativizar a mulher em desempenho político, à época das eleições e pós-eleição, um período bastante representativo no processo político-cultural do Brasil; e, em segundo, ao fato de mostrar a figura feminina no espaço político, espaço este que ainda fica sob os holofotes do noticioso por ser minoria em território habitado primordialmente pelo masculino.

\section{Para uma semântica do designatum}

Pensar em manifestação identitária na linguagem nos leva à tríade da proposta da "virada lingüística", na qual a relação entre sujeito e mundo é intermediada pela linguagem. É pela designação em linguagem que se tem acesso ao mundo. Especificando mais a tríade e dando a ela funções, diríamos que o querer dizer estaria para o sujeito, o dizer para a linguagem e o dito para o mundo; e ampliando o jogo de palavras e de conceitos, o mundo é dito pelo dizer, que por sua vez é acionado por um querer dizer. Esse processo é encaixado à proposta do trabalho, no qual o mundo fala pelo identitário, a linguagem materializa-se em língua e sujeito revela-se no feminino. E especificando mais ainda o campo da linguagem, esta manifesta-se em língua, no qual o foco analítico é a especificidade vocabular da designação.

No texto do Cony, Por uma República Melhor, a designação da mulher versa sobre o atributo da beleza e a do homem sobre o da feiúra, ambos em jogos de poder, este no patamar político e aquela no visual, respectivamente. E nos textos de Antonia Márcia Vale, Companheira Marisa, e de Tina Vieira, A Dona do Alvorada, a figura da primeira dama, esposa do já então Presidente Lula, é configurada pelos atributos de discrição de primeira-dama, de dona de casa que assume tranqüilamente suas funções e de companheira engajada.

Dentre as várias conceituações de referência, vamos ficar com a de Rajagopalan (em prelo, p.1, tradução nossa) que designa que referência é "o ato de referir a uma entidade extralinguíística ou estado de coisas, usando uma expressão referente"; observa-se que a definição aponta a presença de sujeito que pratica um ato de relação ao mundo através da designação, enfim, uma visão subjetiva no ato de referir pela designação. Logo, a designação mergulha em valores subjetivos de cunho sociocultural. 
Grandes teóricos da semântica filosófica norteiam nossa argumentação no processo designativo. Na metáfora do telescópio, Frege (apud RAJAGOPALAN) apresenta o bedeutung como a lente pelo qual o sujeito "vê" e "lê" o mundo, o sentido (zinn) necessita do referente (bedeutung) para conectar-se com o mundo. Logo, a linguagem, em sua natureza nomeativa, é o contato de significação para/com o mundo. Vale também o questionamento de que há vários tipos de expressões referentes: aquela que dá conta de nomes próprios e cargos específicos, a descrição singular, e outra que dá conta de expressões gerais. Tomamos como exemplos termos do texto A Dona da Alvorada: (a) Marisa Letícia da Silva e Primeira-dama estaria para expressões singulares e (b) "dona de casa" (administração de casa) para expressões genéricas. No entanto, Bertand Russell ${ }^{1}$ diz que apenas "nomes logicamente próprios" detêm a natureza de singularidade e que por tal natureza são inomináveis; sua existência estaria para a possibilidade de uma linguagem adâmica. A descrição singular, na realidade, tem referente funcional, atributivo, construindo-se pelo predicado; portanto designações seriam descrições funcionais do objeto e não o objeto em si: primeira-dama, descrição, dona de casa e outros atributos não seriam a Marisa em si, mas atributos que identificam o eu-Marisa Para completar nosso propósito analítico, Peter F. Strawson ${ }^{2}$ diz que expressões fazem referência aos usos em que essas expressões se inserem, usos que se perfilam em contextos históricos em que se alocam.

Este raciocínio nos leva à tese da representação, na qual a linguagem estaria para o re- e a coisa em si para a apresentação. Logo, a apresentação faz-se pela representação. Apresentação estaria quase para uma revelação epifânica que necessita da re-presentação para viabilizar sua aparição material, que seria como um processo mimético de aproximação com o original.

$\mathrm{Na}$ medida em que o sujeito faz parte do ato de referir em linguagem, o ato de referir vai se constituir de uma apresentação política, representada no uso que se faz da linguagem, uso prenhe de crenças políticas que refletem o cultural.

Apud RAJAGOPALAN, em prelo, p.2; tradução da autora.

2 Idem, ib., p.3. 


\section{O utilitarismo político no processo designativo}

Quando se pensa em processo designativo, está-se preso à idéia de que designar Marisa como uma mulher satisfeita com seu universo doméstico não é chegar à identidade desse sujeito, mas perceber que ao sujeito atribuem-se papéis por interesses políticos: valorizar, talvez, a simplicidade de uma mulher, de origem pobre, que chegou ao topo de primeira-dama de um país. No texto A Dona da Alvorada, ao se nomear Marisa de "Espontânea entre amigos, a primeira-dama gosta de ser quem é - e isso encanta quem a conhece.", não se está nomeando a personalidade de Marisa, mas dando um atributo político aos interesses do momento histórico: dizer que a primeira-dama é simples, uma mulher que está feliz com a simplicidade de tarefas cotidianas: "Por enquanto, sua principal ocupação tem sido nos assuntos de que mais gosta: a administração da casa." Essa espontaneidade é ratificada pela presença designativa da ausência de um atributo oposto, a mulher feminista. A alteridade de propriedades, constituída pela categoria do feminismo, enaltece a feminilidade tradicional da dona de casa como complemento do masculino:

Agora, também é a primeira-dama quem cuida pessoalmente do dia-a-dia no Alvorada. Num governo que abriga o maior índice de feministas per capita, até no ministério, ninguém critica Marisa. "Se ela fosse militante, seria melhor", diz Sylvia Camuça, do grupo Articulação das Mulheres Brasileiras. "Mas não temos essa expectativa". O presidente, que se divertia com o discurso feminista quando era dirigente sindical, aprecia o comportamento de Marisa, mulher que se mostrou presente em horas dramáticas de sua vida política.

O mesmo pragmatismo atravessa a designação proposta por Cony, no texto Por uma república melhor, sobre a mulher brasileira, a mulher bela, cuja beleza consegue votos políticos:

Dizem que Cleópatra foi bonita, enfeitiçou dois generais romanos, mas suicidou-se com um picada de cobra. Dizem também que não era tão bonita assim, tinha o nariz adunco como o de uma águia. E, naquele tempo, em que pese a excelência da medicina egípcia e de suas mandingas miraculosas, não havia nenhum Ivo Pitanguy por lá dando sopa. A rainha Vitória era feia, quase anã e Catarina, a Grande, também não era lá essas coisas. 
O trono não embeleza necessariamente ninguém, embora o poder tenha alguma coisa de excitante. Entre ir para a cama com a Demi Moore plebéia ou com a rainha-mãe da Transilvânia, acho que não perderia um segundo para decidir. Trago o assunto porque, de repente, após a meteórica e deslumbrante passagem de Roseana Sarney pela disputa presidencial, a classe política, tradicionalmente formada por homens feios, alguns até horripilantes, descobriu que mulher bonita pode dar voto.

$\mathrm{O}$ autor faz o jogo designativo entre as expressões beleza, feiúra e poder, na medida em que as categorias beleza e feiúra açambarcam a idéia de poder, o poder feio e mal usado pelo masculino no exercício político que necessita da beleza física feminina para adquirir comportamento positivo: Já é tempo de melhorarmos o visual republicano. Seria um ponto de partida para melhorarmos a nossa própria República. O pragmatismo está na denúncia contra a feiúra performativa dos políticos masculinos. Apesar do caráter positivo dado aos atributos femininos, revelam-se valores ideológicos de que as mulheres aparecem no cenário político brasileiro apenas por sua capacidade de sedução da beleza física. O euforismo do visual feminino se reduz ao plano sensorial, pois na prática política é meteórica. Naquele instante, o construto identitário feminino estabelece-se como instrumento de crítica política contra o masculino, que, sob uma ideologia patriarcal, configura a não-performatividade política do feminino ao enaltecer seu poder físico:

A escolha de Rita Camata para vice de Serra teve essa finalidade. E é possível que os demais candidatos presidenciais estejam procurando uma parceira com visual que dê para compensar a feiúra estrutural dos cabeças de chapa.Sugiro uma repescagem num terreno fértil de mulheres boazudas que agradam à plebe. As madrinhas de baterias das escolas de samba estão aí, seriam excelentes reservas. Nada tenho contra elas e, honestamente gostaria de ver Luíza Brunet, Luma de Oliveira, Vera Fischer, Adriane Galisteu e até mesmo a veterana Dercy Gonçalves como opções de poder em caso de emergência constitucional. 


\section{$\mathrm{O}$ imaginário-cultural no designatum}

Os nominata, objeto nomeado que aponta para lá-fora, indicativos de figuras femininas, são os nomes funcionais dados ao objeto mulher; a cada expressão sobre a mulher - ou dona de casa, simples, que faz o que gosta, ou mulher bonita que dá votos modificam-se funções que são trocadas/substituídas pelo predicado identitário da mulher; o conjunto de variáveis atributivas é preenchido a cada momento do ato designativo. Mas a questão fica para além do utilitarismo do aqui-agora, quando se propõe pensar qual a ligação entre o indivíduo - Marisa, Roseana Sarney, Rita Camata - e sua representação social, e como esta se delineia no cultural. Parece-nos que as designações que trabalham na identificação dos indivíduos

podem nos fornecer pistas preciosas e bem atuais das relações sociais e culturais que se estabelecem entre homens e mulheres e os significados a elas atribuídos.

A lente que capta a referência mostra o mundo identitário do instante designativo, mas a nomeação pode também configurar uma re-atualização do passado, do imaginário, de uma história cultural.

Percebe-se o contínuo embate entre as fronteiras do individual e o social. De um lado, o instante performativo do utilitarismo com sua heterogeneidade manifesta, de outro, a presença do imaginário que reflete a homogeneidade do cultural. Um não é excludente do outro, pois o movimento desses dois patamares é de sobreposição e não de causalidade. O paradoxo se delineia pela convivência da durabilidade de uma dimensão que parece homogênea, que se alimenta do performativo. Os atributos designativos, enquanto performativos, de alguma forma tem seu bedeutung "ampliado" na história do objeto referido. O nominatum, o nome do objeto, pelo designatum, a "idéia" do objeto, reconhece o cultural (coletivo) alimentado pelo imaginário (individual inserido no coletivo) do sujeito situado em sua história.

O imaginário dimensiona os modos de fazer do sujeito, porquanto imaginário é um parâmetro cultural. O imaginário é medido pela coletividade cultural, é um espelho da cultura, é uma construção histórica. E na medida em que imaginário é pulsão do ser humano, e que sujeito e mundo se intercambiam via linguagem, imaginário circula na linguagem. Os outros do mundo se presentificam na

Cf. Martins, em prelo, p.2. 
dimensão imagética cultural que habita em cada sujeito, dimensão que oferece "estradas" identitárias, isto é, quais modelos devo seguir para constituir um eu identitário. O imaginário projeta um figurino que atenda os interesses do jogo sócio-histórico; é uma busca de um eu estabilizado visto pelo outro. Na busca de uma homogeneidade, o sujeito se estabiliza na diversidade do vivido, o que mostra que a unidade é da dimensão do imaginário, a estabilidade é provida no universo imaginário; é uma forma, talvez, de sedimentar e impedir a cisão do multiculturalismo.

\section{Práxis e simbolismo, um convívio paradoxal}

O processo designativo além de ser regido pelo imaginário, desvenda o símbolo por detrás do interesse das práticas da vida cotidiana. Pensar nos símbolos da figura feminina contida na propriedade beleza e na função dona de casa e companheira tende a apagar as contradições, as lutas de poder e os interesses materiais. A criação e, no caso, a re-criação simbólica de "amélia", demonstra as imposições da esfera sócio-política; a mudança está na designação do já vivido, o passado é re-apresentado, apresentado de novo. O texto Companheira Marisa, de Antônia Márcia Vale, ilustra a questão do simbólico:

Durante a campanha, ela esteve sempre ao lado do marido, que por sua vez se desdobrou em elogios e gestos públicos de carinho, como nunca se vira antes na vida pública brasileira. O casal Marisa Letícia e Luiz Inácio Lula da Silva trouxe para o Planalto um comportamento que foi símbolo da revolução nas relações entre homens e mulheres nas décadas de 60 e 70: o companheirismo .É conversando com Marisa que Lula toma as decisões mais difíceis.

4 A etimologia de Amélia ou Amália poderia explicar a metáfora proposta ao significar uma laboriosa abelha ou uma formiguinha, pois essa mulheramélia, igual à abelha e à formiga, trabalha incógnita e incansavelmente, no seu dia-a-dia, sem reclamar, em prol de seu grupo familiar. Mas também podemos aliar a etimologia do termo à letra de uma música tradicional brasileira, muito conhecida, que canta uma mulher chamada Amélia, cujo cognome é "a mulher-de-verdade". Em ambas as colocações, Amélia é o símbolo da feminilidade, da companheira do homem em e para todos os momentos. 
É o que Shalins (2003, p.63) nos indica, a partir da antropologia e disciplinas correlatas, que se tem na simbologia "uma versão do passado como ele é realmente vivido por um segmento da sociedade, como o mapa da sua condição presente". É os símbolos do companheirismo feminino, que se quisermos remonta ao mundo de Penélope, sempre à espera de seu marido Ulisses.

No mundo simbólico, "olho que vê é o órgão da tradição" (SAHLINS, 2003,p. 70), tradição sendo entendida como um conjunto. de significados acumulados, vividos na história que faz de uma percepção designativa uma concepção, advinda da práxis social na sua especificidade histórica.

A proposta aqui não é desmascarar o interesse político por detrás do símbolo, mas desvendar o símbolo que está por detrás do utilitarismo. Ao mostrar a primeira-dama como a companheira engajada nos interesses nacionais, vestida de vermelho em homenagem ao Sindicato dos Trabalhadores, com enfeites e roupas de grife nacionais, a identidade de Marisa, a serviço de interesse, também se adequa ao mundo do imaginário simbólico, da mulher que soma, que completa o masculino, da mulher adâmica que nasce da costela do homem. Portanto, práticas sociais, práticas designativas advindas da práxis social desvendam símbolos na vida cotidiana:

Dona Marisa concluiu que é hoje uma das mulheres mais observadas do País e o que usar será imitado. A indústria da moda é a segunda maior empregadora do País, só perde para a construção civil e, ao usar e divulgar os produtos nacionais, ela quer colaborar para que seu companheiro realize a 'obsessão' de gerar novos empregos para os brasileiros. Na cor da roupa homenageou o Partido dos Trabalhadores, na escolha dos materiais e criadores dos trajes inaugurou o 'estilo Marisa' usando produtos exclusivamente nacionais de excelente qualidade, mas sem ostentação. O vestido foi desenhado e confeccionado em musseline brasileira pelo estilista Walter Rodrigues. Sapatos e bolsa são da grife Ferri, de São Paulo.

Parece-nos que o conflito entre utilitarismo e enfoque cultural não deve ser medido por um condicionamento irrestrito entre as duas dimensões, até porque o conflito se esvai na relação que se estabelece entre as "partes" (SAHLINS, 2003, p.61): 
se a ordem cultural tem de ser concebida como a codificação da ação intencional e pragmática real do homem, ou se, ao contrário, a ação humana no mundo deve se compreendida como mediada pelo projeto cultural, que ordena imediatamente a experiência prática. a prática ordinária, e o relacionamento entre as duas.

A semelhança de traços conceptuais, perfiladora da unicidade cultural, constitui-se das "diferenças em significados e usos determinados localmente" (SAHLINS, 2003, p. 73). Não há fronteiras delimitadas entre o universo cultural, a prática social e o performativo individual, até porque um não deriva automaticamente do outro. Cultura padroniza traços pela especificidade do particular; enquanto totalidade, é regida por idéias dominantes, que se fazem dominantes porque surgem da diferença do que é não-dominante. Se déssemos à cultura um caráter unívoco de significação estaríamos mais para classificação redutora de identidades do que para a representação sócio-histórica. História é construto, é resultado de performativos transformadores.

O que se percebe é que nenhuma das bandas é excludente uma da outra, pois há um contínuo movimento anatômico de performativos sociais que modelam a cultura e o imaginário que fazem parte do processo designativo e que, por sua vez, manifestam-se em uso de língua. Essa relação não pode ser senão uma superposição. Sem dúvida nenhuma, a práxis social e a linguageira estão sujeitas às formulações designativas da cultura e vice-versa. Deve-se ficar claro que a "orientação do efeito lógico", levam á prática e que se organiza e codifica institucionalmente, não faz sentido, pois o processo não é de causalidade linear, mas de um tipo de convivência anatômica.

Utilitarismo do uso designativo pode reforçar as significações já cristalizadas no sociocultural, desvelando a durabilidade de um referente modalizado, que atende a significações simbólicas. No fundo, percorremos um caminho metodológico que visou apresentar a representação do feminino, seus usos designativos, que se influenciam pelo imaginário no ato de referir, designando em relação a um referente até simbólico, que perpassa a cultura dos sujeitos.

${ }^{5}$ Morgan, apud Sahlins, 2003, p. 66. 
174 LEITURA - ESPAÇOS HÍBRIDOS: n.28, jul./dez. 2001; n.29, jan.jjun. 2002

Como diz Rajagopalan, o poder da designação é maior do que se possa imaginar, pois alimenta tanto mudanças como interpretações fantasiosas das mesmas:

A mídia imprime certas interpretações pelo simples ato de designação de determinados acontecimentos(...) Posto que, de acordo com certas teorias semânticas de grande prestígio, os nomes não passam de meras etiquetas identificadoras de objetos, é preciso pensar além da semântica dos nomes próprios para encarar o fenômeno de nomeação como um ato eminentemente político. ${ }^{6}$

A designação é sempre representação nunca apresentação da coisa em si, do ser feminino. O ser feminino é representado por designações, designações que forjam sentidos e referentes induzidos pelo momento utilitário de um sujeito, de um grupo, de uma cultura:

designação é um processo pelo qual nós damos uma habitação local e um nome para um objeto(...)talvez o mais importante passo para a manipulação ideológica. ${ }^{7}$

No jogo entre sujeito, linguagem e mundo, poderíamos afirmar que identidade é um construto de atributos que se alinham ao longo da história, porquanto designações, sob o ponto de vista pragmaticista e/ou simbólico, "são nada mais que representações verbais de atributos e atributos são da ordem de acidente (e não de essência)" (RAJAGOPALAN, ob.cit., p.4), de um presente ou de um passado re-atualizado: mundos de referentes, nos permeiam que nos constroem e que construímos.

O construto identitário estaria para um efeito Penélope construir, desconstruir, construir em busca de uma fiação ideal que tanto atende ao instante do ato de referir quanto reflete valorações do sistema simbólico-cultural em que habita. O ato designativo constrói sua própria avaliação do objeto atribuído.

Rajagopalan, p.3.

Rajagopalan, ibidem, p.1, abstract, tradução da autora . 
A CONSTRUÇĀO DA IDENTIDADE DO FEMININO :

PRAGMATISMO, IMAGINÁRIO E SIMBÓLICO

\section{Referências bibliográficas}

FELDMAM-BIANCO, B. e CAPINHA, G. (orgs.). Identidades Estudos de cultura e poder. São Paulo: Hucitec, 2000.

FERREIRA, Dina. Discurso Feminino e Identidade Social. São Paulo: FAPESP/Annablume, 2002.

FERREIRA, Dina (pre-print). Political discourse in the feminine manifestation: social identity (Queen Marianna of SpaIn and Governor Roseana of Maranhão). In: Image 2002, Alborg University, Denmark.

FERREIRA, Dina. Culture and society - the identity of the feminine manifestation. Journal of Language and Linguistics, vol. 2, issue 1, $<$ http://www.jllonline.net $>, 2003$.

MARTINS, Eneida. (em prelo) Os nicknames nas salas da Internet: novos nomes, velhos mitos.

RAJAGOPALAN, K. Designação a arma secreta, porém incrivelmente poderosa, da mídia em conflitos internacionais. (em prelo a).

RAJAGOPALAN, K. Reference In Fitzroy-Dearborn Encyclopedia of Linguistics. Chicago: (em prelo b).

SAHLINS, Marshall. Cultura e razão prática. Rio de Janeiro: Zahar, 2003.

ZIZEK, Slavoj. O paradigma das ideologias. Folha de S. Paulo, Caderno Mais!, 4 de agosto de 2002, p.3. 